
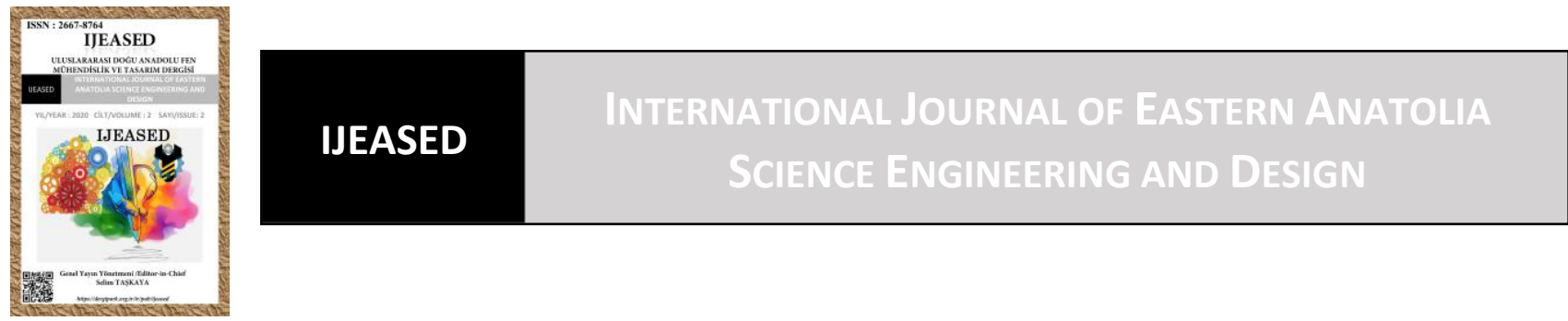

\author{
Uluslararası Doğu Anadolu Fen Mühendislik ve Tasarım Dergisi \\ ISSN: 2667-8764, 2(2), 262-274, 2020 \\ https://dergipark.org.tr/tr/pub/ijeased
}

Araştırma Makalesi / Research Article

Doi: $\underline{10.47898 / \text { ijeased.786830 }}$

\title{
Yaşamın Farklı Alanlarında Mittag-Leffler Fonksiyonu
}

\author{
Hüseyin ŞİRIN ${ }^{1 *}$, Abdullah Engin ÇALIK ${ }^{1}$
}

${ }^{1}$ Ege Üniversitesi, Fen Fakültesi, Fizik Bölümü, İzmir, 35040, Türkiye.

\begin{tabular}{|c|c|c|}
\hline Yazar Kimliği / Author ID (ORCID Number) & \multicolumn{2}{|c|}{ Makale Süreci / Article Process } \\
\hline "Sorumlu Yazar / Corresponding author: & Geliș Tarihi / Received Date & 28.08 .2020 \\
\hline huseyin.sirin@ege.edu.tr & Revizyon Tarihi / Revision Date : & 27.09 .2020 \\
\hline (iD) https://orcid.org/0000-0002-2514-3935, H. Sirin & Kabul Tarihi / Accepted Date : & 17.10 .2020 \\
\hline (iD https://orcid.org/0000-0003-3441-6496, A. E. Çalık & Yayım Tarihi / Published Date : & 15.12 .2020 \\
\hline
\end{tabular}

Alıntı /Cite : Şirin, H., Çalık, A.E. (2020). Yaşamın Farklı Alanlarında Mittag-Leffler Fonksiyonu, Uluslararası Doğu Anadolu Fen Mühendislik ve Tasarım Dergisi, 2(2), 262-274.

\section{Özet}

Bu çalışmada kesirsel kinetik denklemin farklı çözümlerinde karşımıza çıkan ve eksponansiyel fonksiyonu genelleyen Mittag-Leffler (ML) fonksiyonu ele alınmaktadır. ML fonksiyonu yardımıyla nüfus, sera gazı salınımı ve dış ticaret hacmi süreçlerindeki artma dinamikleri incelenmektedir. Bu amaçla bu süreçler için grafiksel gösterimler yapılmakta ve gerçek veriler ile karşılaştırılmaktadır. Kesirsel türev mertebesi yardımıyla gerçek değerler ile teorik hesaplamaların arasındaki uyum incelenmektedir.

Anahtar Kelimeler: Mittag-Leffler Fonksiyonu; Kesirsel matematik; Bellek Etkisi.

\section{Mittag-Leffler Function in different areas of life}

\begin{abstract}
In this work, Mittag-Leffler $(M L)$ function that is encountered in different solutions of fractional kinetic equation and generalizes exponential function has been handled. With the help of ML function, growth dynamics of population, foreign trade volume and greenhouse gas emission have been investigated. With this manner, graphical representations for these processes have been compared with real data. The harmony between theory and real data has been investigated with the help of order of fractional derivative.
\end{abstract}

Keywords: Mittag-Leffler Function; Fractional Calculus; Memory Effect. 


\section{Giriş}

Doğadaki süreçler gerçekte nasıl davranmaktadır sorusu fen ve mühendislik bilimlerinde cevabı aranan başlıca konulardandır. Bu sorunun cevaplarında öne eksponansiyel ve kuvvet formunda fonksiyonlar çıkmaktadırlar (Marquet ve ark. 2005, Keeling 2000, Keitt ve ark. 2002, Keitt ve Stanley 1998, Stanley ve ark. 1996, Shimojo 2014, Shimojo ve Nakano 2013). Doğada, yaşamda, fen ve mühendislik bilimlerinde birçok araştırmada, fiziksel süreçleri temsil eden diferansiyel denklemlerin çözümlerinin çoğunda eksponansiyel fonksiyon ile karşılaşılmaktadır (Vandermeer 2010, Vacher 2000, Ricketts ve ark. 1999). Nüfus artış1 (Bowen ve ark. 2003, Keiding 1975), mikroorganizmaların çoğalması (Vandermeer 2010), jeokronoloji (Vacher 2000), NASA astronotlarının kemik mineral kaybı (Sibonga ve ark. 2007), ekonomi (Silva ve ark. 2004, Sabatelli 2002), kanser (Holland ve ark. 1999), pandemi (Verma ve ark. 2020) vb. doğada ve günlük yaşantımızda eksponansiyel azalma veya artma ile ilgili bunlara benzer daha birçok örnek verilebilir. Eksponansiyel fonksiyonların genelleştirilmesi ve belli modellerde kullanılması da yapılan çalışmalar arasındadır (Martinez ve ark. 2009, Nivanen ve ark. 2003).

Bir sistemin veya fiziksel bir sürecin gelecekte nereye evrileceği sorusu da sıkça sorulmakta ve cevap aranmaktadır (Büyükkılıç ve Demirhan, 2009, Çalık ve Şirin, 2017). Fiziksel süreçlerin zaman ve/veya uzayda evrilmesi diferansiyel denklemler aracılı̆̆ çok kullanılan diferansiyel denklem formlarından biri olan

$$
\frac{d y(t)}{d t}=\mp \lambda y(t)
$$

birinci mertebeden, lineer ve homojen diferansiyel denkleminin çözümü;

$$
y(t)=y_{0} e^{\mp \lambda t}
$$

şeklinde eksponansiyel fonksiyon cinsinden elde edilmektedir. (1) diferansiyel denklemi, kinetik denklem (Saxena ve ark. 2002, Haubold ve Mathai 2000), nükleer bozunma denklemi (Krane 1998), relaksasyon denklemi (Hilfer 2000, Hilfer 2003) gibi birçok isimlendirmeye sahiptir.

$\mathrm{Bu}$ kadar çok karşımıza çıkan eksponansiyel fonksiyon genel olarak sistemlerin davranışı hakkında bir fikir verse de gerçeğe yakın tasvir edilen sistemlerden elde edilen veri ile uyumlu değildir. Sistemin üzerindeki etkileri açıklamakta yetersiz kalmaktadır (Vandermeer 2010). Daha önce yapılan farklı alanlardaki çalışmalarda gerçek veri ile olan uyumsuzluk görülmüş ve bu uyumsuzluk kesirsel matematik kullanılarak giderilmeye çalışılmıştır: 
Nükleer bozunma denklemi ilk defa Caputo kesirsel türevi uygulanarak "kesirsel nükleer bozunma denklemi” olarak yeniden tanımlanmış ve çözülmüştür (Çalık ve ark. 2013). Elde edilen bu yeni çözüm kullanılarak alfa bozunması (Çalık ve ark. 2013) ve proton bozunması (Çalık ve ark. 2014) yapan çekirdeklerin yarı-ömür değerleri deneysel veri ile uyum içinde elde edilmiştir. Hesaplamalara herhangi bir keyfi parametre eklenmemiş, kesirsel yarı-ömür ifadesi ML fonksiyonu cinsinden elde edilmiştir. Kesirsel türev mertebesinin de nükleer yapıya nasıl bağlı olduğu araştırılmıştır.

Beta parçacık şiddetinin soğurucu bir malzemenin kalınlığına bağlı olarak değişimini ifade eden soğurulma denklemi ilk defa "kesirsel soğurulma denklemi”" olarak yeniden tanımlanmış ve çözülmüştür (Şen ve Çalık 2014). Alüminyum soğurucuların yarı-değer kalınlıkları (Şen ve Çalık 2014; Şen ve ark. 2014), farklı tipte üretilen harç malzemelerinin yarı-değer kalınlıkları (Çalık ve Şirin 2018), alüminyum soğurucuların onuncu-değer kalınlıkları (Şen ve ark. 2019) ve polietilen soğurucuların yarı-değer kalınlıkları (Çalık ve ark. 2020) deneysel değerler ile uyum içinde hesaplanmıştır. Kesirsel türev mertebesi tüm hesaplar için yaklaşık 0,3 civarında elde edilmiştir. Böylece farklı beta kaynakları ve farklı soğurucular kullanılmasına rağmen yaklaşık aynı kesirsel türev mertebesi değerinde deneysel ve kesirsel yarı-değer ve onuncu-değer kalınlıklarının elde edilmesi ile standart soğulma denkleminin yerine kesirsel soğurulma denkleminin kullanılmasının gerektiği sonucuna ulaşılmıştır.

RC devresinde zamanla kondansatörün yükünün değişimini ifade eden diferansiyel denklem kesirsel olarak yeniden tanımlanmış ve çözülmüştür (Ertik ve ark. 2015). Literatürdeki diğer çalışmalardan farklı olarak Planck birimleri kullanılarak boyutsuzlaştırma yapılmıştır. Kesirsel türev mertebesinin farklı değerleri için hesaplamalar yapılmış ve deneysel sonuçlarla uyumlu olan kesirsel türev mertebesi elde edilmiştir. Benzer şekilde LC devresinde de yükün zamana göre değişimini veren ikinci mertebeden diferansiyel denklem Caputo kesirsel türevi kullanılarak yeniden tanımlanmış ve çözülmüştür (Çalık ve ark. 2016).

Türkiye'nin geçmiş y1llarda elektrik enerjisi tüketimi, Türkiye İstatistik Kurumu verilerinden alınarak yıllara göre nasıl bir değişim gösterdiği, bu değişimin nelere bağlı olduğu, sonraki yıllarda artan nüfus ve elektrikli cihaz sayısına bağlı olarak yapılması gereken elektrik enerjisi yatırımlarının neler olduğu araştırılmıştır. Geleceğe yönelik olarak enerji ihtiyacının ne kadar olacağını tahmin eden çalışmalar incelenmiştir. Türkiye'nin geçmiş yıllardaki elektrik enerjisi tüketiminden yola çıkarak, kesirsel matematik kullanılarak bir modelleme yapılmış ve gelecek yıllarda Türkiye'nin elektrik enerjisi ihtiyacının ne olabileceği tahmin edilmeye çalışılmıştır (Çalık ve Şirin 2017). 
Newton soğuma kanunu olarak ifade edilen, bir maddenin sıcaklığının zamanla değişimini veren diferansiyel denklem kesirsel matematik kullanılarak yeniden tanımlanmış ve çözülmüştür (Şirin ve Çalık 2019). Hesaplamalar kesirsel türev mertebesinin farklı değerleri için yapılmış ve deneysel sonuçlarla karşılaştırılmıştır.

$\mathrm{Bu}$ çalışmada ise, artış veya azalış gösteren süreçleri incelemek için kullanılan kinetik denklem kesirsel matematik ve kümülatif küçülmeler /büyümeler metodu ile tanıtılarak ele alınacak ve bu metodların çözümünden elde edilen ML fonksiyonu kullanılarak farklı alanlardaki gerçek verilerle farklı türev mertebeleri için karşılaştırılmaları yapılacaktır.

$\mathrm{Bu}$ çalışmanın girişi takip eden ikinci bölümünde kesirsel kinetik denklem ve Mittag-Leffler fonksiyonu tanitılmakta, üçüncü bölümde artan veya azalan süreçleri temsil eden kümülatif küçülmeler büyümeler metodu incelenmekte, dördüncü bölümde ise gerçek yaşamdan verilerle görsel kıyaslamalar yapmak için farklı kesirsel türev mertebeleri ile grafiksel gösterimler yapılmaktadır.

\section{Kesirsel Kinetik Denklem ve Mittag-Leffler Fonksiyonu}

19. yy başlarında ortaya çıkan kesirsel matematik günümüzde de fen ve mühendislik bilimlerinde sıkça kullanılmaktadır (Hilfer 2000, Podlubny 1999). İçerisine bellek etkisi ve fraktallık barındıran sistemleri standart matematiksel yöntemlerle incelemek yerine bu etkileri içine alacak matematiksel yöntemler kullanmak gerekmektedir.

Doğanın fraktal ve bellek etkisi özellikleri nedeniyle kesirsel matematiksel yöntemler tercih edilmektedir. Fiziksel süreçleri temsil eden diferansiyel denklemleri gerek lineer gerekse non-lineer olsun standart matematik yerine kesirsel matematiksel yöntemlerle çözmek sürecin mevcut ve gelecekteki durumunu incelemek açısından daha doğru olmaktadır. Kesirsel matematiksel yöntemlerle ilgili kullanılan farklı türev ve integral operatörleri mevcuttur. Örneğin GrünwaldLetnikov türev tanımı nümerik hesaplama yapanlar tarafından tercih edilirken, Riemann-Liouville ve Caputo türev tanımları ise analitik hesaplamalarda kullanılır. Riemann-Liouville ve Caputo türev tanımları arasındaki temel fark ise sabitin türevinin sıfır olması durumudur. $\mathrm{Bu}$ nedenle Caputo kesirsel türev tanımı daha çok fizikçiler tarafından tercih edilmektedirler. Grünwald-Letnikov (GL), Riemann-Liouville (RL) ve Caputo (C) kesirsel türev tanımları sırasıyla aşağıdaki gibi verilmektedir (Podlubny, 1999); 


$$
\begin{aligned}
& D_{G L}^{\alpha} f(t)=\sum_{k=0}^{m} \frac{f^{k}(a)(t-a)^{-\alpha+k}}{\Gamma(-\alpha+k+1)}+\frac{1}{\Gamma(-\alpha+m+1)} \int_{a}^{t}(t-\tau)^{m-\alpha} f^{m+1}(\tau) d \tau \quad m<\alpha<m+1 \text {, } \\
& D_{R L}^{\alpha} f(t)=\left\{\begin{array}{cc}
\frac{d^{m}}{d t^{m}}\left[\frac{1}{\Gamma(m-\alpha)} \int_{0}^{t} \frac{f(\tau)}{(t-\tau)^{\alpha+1-m}} d \tau,\right. & m-1<\alpha<m] \\
\frac{d^{m}}{d t^{m}} f(t), & \alpha=m,
\end{array}\right. \\
& D_{C}^{\alpha} f(t)=\left\{\begin{array}{cl}
\frac{1}{\Gamma(m-\alpha)} \int_{0}^{t} \frac{f^{m}(\tau)}{(t-\tau)^{\alpha+1-m}} d \tau, & m-1<\alpha<m \\
\frac{d^{m}}{d t^{m}} f(t), & \alpha=m .
\end{array}\right.
\end{aligned}
$$

Fiziksel bir süreç zaman ve uzayda evrilerek hareket eder. Standart yaklaşımda fiziksel bir sürecin evriminin Euclidian ve Markovian bir doğaya sahip olduğu kabul edilir. Fakat gerçek sistemler, sistemin kompleksliğinden, uzayın veya zamanın kesikliliğinden kaynaklı farklı bir davranış sergilerler. Bu sistemler non-Euclidian ve non-Markovian bir yapıya sahiptirler(Herrmann 2011, Hilfer 2000). Bu nedenle, standart hesaplamalar doğanın daha gerçekçi bir tasvirini yaparken yetersiz kalmaktadırlar. Başka bir deyişle, doğanın ve doğadaki kuramların standart matematiksel yöntemlerle ele alınması durumunda elde olunan veriler ile deneysel veya gerçek hayattan alınan veriler arasında bir uyum bulunmamaktadır. Kesirsel matematik bu noktada önem kazanmakta ve fiziksel süreçlerin daha gerçekçi incelenmesinde bir araç olmaktadır. Doğa non-lokal ve/veya nonMarkovian (bellek etkisi içeren) davranışlar sergiler, bu nedenle bu davranışları içinde bulunduran kesirsel matematiği kullanmak daha doğru gözükmektedir.

(1) denklemi,

$$
\frac{d}{d t} \rightarrow \frac{d^{\alpha}}{d t^{\alpha}}
$$

dönüşümü yapılarak, kesirsel matematiksel yöntemler ele alınarak çözüldüğünde (Çalık ve ark. 2018, Büyükkılıç ve Demirhan 2009, Çalık ve ark. 2014, Çalık ve Şirin 2017, Çalık ve Şirin 2018, Şirin ve Çalık, 2019)

$$
\begin{aligned}
& \frac{d^{\alpha} y(t)}{d t^{\alpha}}=\mp \lambda y(t) \\
& y(t)=y_{0} \sum_{k=0}^{\infty} \frac{(\mp \lambda t)^{k}}{\Gamma(\alpha k+1)} \\
& y=y_{0} E_{\alpha}(\mp \lambda t)
\end{aligned}
$$

şeklinde elde edilir, burada $E_{\alpha}(\lambda t)$ Mittag-Leffler fonksiyonu olarak adlandırılır (Podlubny 1999, Oldham ve Spainer 2006, Miller ve Ross 1993). ML fonksiyonu $\alpha=1$ değerinde eksponansiyel fonksiyonu vermektedir. Kuvvet ve eksponansiyel formu açıklamakta kullanılan ML fonksiyonu 


$$
E_{\alpha}(x)=\sum_{k=0}^{\infty} \frac{x^{k}}{\Gamma(\alpha k+1)}
$$

ile verilir ve tek parametreli ML fonksiyonu olarak adlandırılır. Genelleştirilmiş ML fonksiyonu ise

$$
E_{\alpha, \beta}(x)=\sum_{k=0}^{\infty} \frac{x^{k}}{\Gamma(\alpha k+\beta)}
$$

ile verilir. ML fonksiyonunun bazı özellikleri;

i. $\quad E_{1,1}(x)=e^{x}$

ii. $\quad E_{2,1}\left(x^{2}\right)=\cosh (x)$

iii. $\quad E_{2,2}\left(x^{2}\right)=\frac{\sinh (x)}{x}$

iv. $\quad E_{\frac{1}{2}, 1}(x)=e^{x^{2}} \operatorname{erfc}(-\mathrm{x})$ burada $\operatorname{erfc}(x)$ hata fonksiyonudur.

İki paremetreli ML fonksiyonu ile ilişkili olan Wright fonksiyonu ise lineer kısmi diferansiyel denklem çözümlerinde rol almaktadır.

\section{Kümülatif Küçülmeler Büyümeler Metodu}

Fiziksel süreçlerdeki artış veya azalış durumlarını Büyükkılıç ve Demirhan (2009) tarafından ortaya konulan kümülatif küçülmeler/büyümeler metoduyla incelemek mümkündür (Büyükkılıç ve Demirhan 2009, Büyükkılıç ve ark. 2015, Büyükkılıç ve ark. 2016). Süreç başladığında $(t=0)$ anında problemdeki miktarın $N_{0}$ kadar olduğu kabul edilirse $\Delta t$ süre geçtikten sonra $\lambda \Delta t N_{0}$ artışla $N_{1}$ miktarına, $2 \Delta t$ süre geçtikten sonra da $\lambda \Delta t N_{1}$ miktarına ulaşacaktır. Bu süreç

$$
\begin{array}{ll}
t=0 & N_{0} \\
t=\Delta t & N_{1}=N_{0}+\lambda \Delta t N_{0}=N_{0}(1+\lambda \Delta t) \\
t=2 \Delta t & N_{2}=N_{0}(1+\lambda \Delta t)^{2} \\
\cdot & \\
\cdot & \\
t=n \Delta t & N_{n}=N_{0}(1+\lambda \Delta t)^{n}
\end{array}
$$

şeklinde ilerletilirse, $n$. adımda

$$
N_{n}=\phi^{n} N_{0}
$$

yazilabilir. Burada $\phi=(1+\lambda \Delta t)$ ve $t=n \Delta t$. Bu denklem 


$$
N_{n}(\lambda \Delta t)=\sum_{k=0}^{n}\left(\begin{array}{l}
n \\
k
\end{array}\right)(\lambda \Delta t)^{k} N_{0}
$$

şeklinde yazılabilir, burada $\left(\begin{array}{l}n \\ k\end{array}\right)$ Binom katsayılarıdır. Bu denklemin çözümü ise (Büyükkılıç ve Demirhan, 2009);

$$
N(\lambda, t, \alpha)=E_{\alpha}(\lambda t) N_{0}=\sum_{k=0}^{n} \frac{(\lambda t)^{k}}{\Gamma(\alpha k+1)} N_{0}
$$

olarak ML fonksiyonu cinsinden elde edilir.

(5) ve (7) denklemlerinden görüldüğü gibi fiziksel artan veya azalan süreçler ML fonksiyonu cinsinden elde edilmektedirler.

\section{Uygulamalar}

$\mathrm{Bu}$ kesimde kinetik denklemin çözümünü olan ML fonksiyonu yardımıyla doğa ve yaşamdan bazı süreçlerin grafiksel gösterimleri verilmektedir. (5) denklemi ile verilen çözüm yardımıyla Türkiye'deki nüfus artışı, sera gazı salınım miktarları, dış ticaret hacmi örnekleri ele alınmaktadır. $\mathrm{Bu}$ örneklerde mevcut veri ile çalışılarak ve ileriye dönük tahminlerde bulunulması amaçlanmaktadır. (5) denkleminin fiziksel süreçlerden elde edilen gerçek verileri incelemede daha başarılı olması beklenmektedir. $\mathrm{Bu}$ amaçla kesirsel türev mertebesi $\alpha$ 'ya göre gerçek verilerin yıllara göre değişimi şekil 1, şekil 2 ve şekil 3’te verilmektedir.

\subsection{Sera Gazı Salınımı}

Son yıllardaki yaşantımızın şekli ve ilerleyişi çevreye yaptığı etkilerle ön plana çıkmaktadır. 1972 yılındaki Stockholm Konferansı ile başlayan çevresel sorunları inceleme süreci, 2015 yılındaki Paris İklim Zirvesine kadar gelmiştir. Günümüzde ise çevresel sorunlar artık ciddi seviyelere ulaşmıştır. Sera gazı seviyelerinin verdiği zararları göz önüne aldığımızda ileriki yıllarda hangi seviyelerde çevresel sorunlarla karşılaşacağımızı bilmek önem arz etmektedir. Bu nedenle sera gazı tahminleri de önemli araştırma konularından biridir. Boğar ve Boğar (2017) çalışmalarında enerji, endüstriyel işlemler, ürün kullanımı, tarımsal faaliyetler ve atıklar başlıkları altında, Pabuçcu ve Bayramoğlu (2016) ise nüfus, GSYİH (gayri safi yurt içi hasıla), enerji üretimi/tüketimi ve ulaşım için enerji tüketimi başlıkları altında yapay sinir ağları modeli ile Türkiye'deki 2030 yılına kadar $\mathrm{CO}_{2}$ salınım miktarını tahmin etmişlerdir. Çeşmeli ve Pençe (2020) makine öğrenimi yöntemi ile 2031 yılına kadar Türkiye'deki sera gazı salınım miktarını tahmin 
etmişlerdir. Şekil 1'de, $\alpha=0,305345$ ve $\lambda=0,02$ değeri için mevcut verilerden hareketle gelecek y1llara ait tahmin verilmektedir.

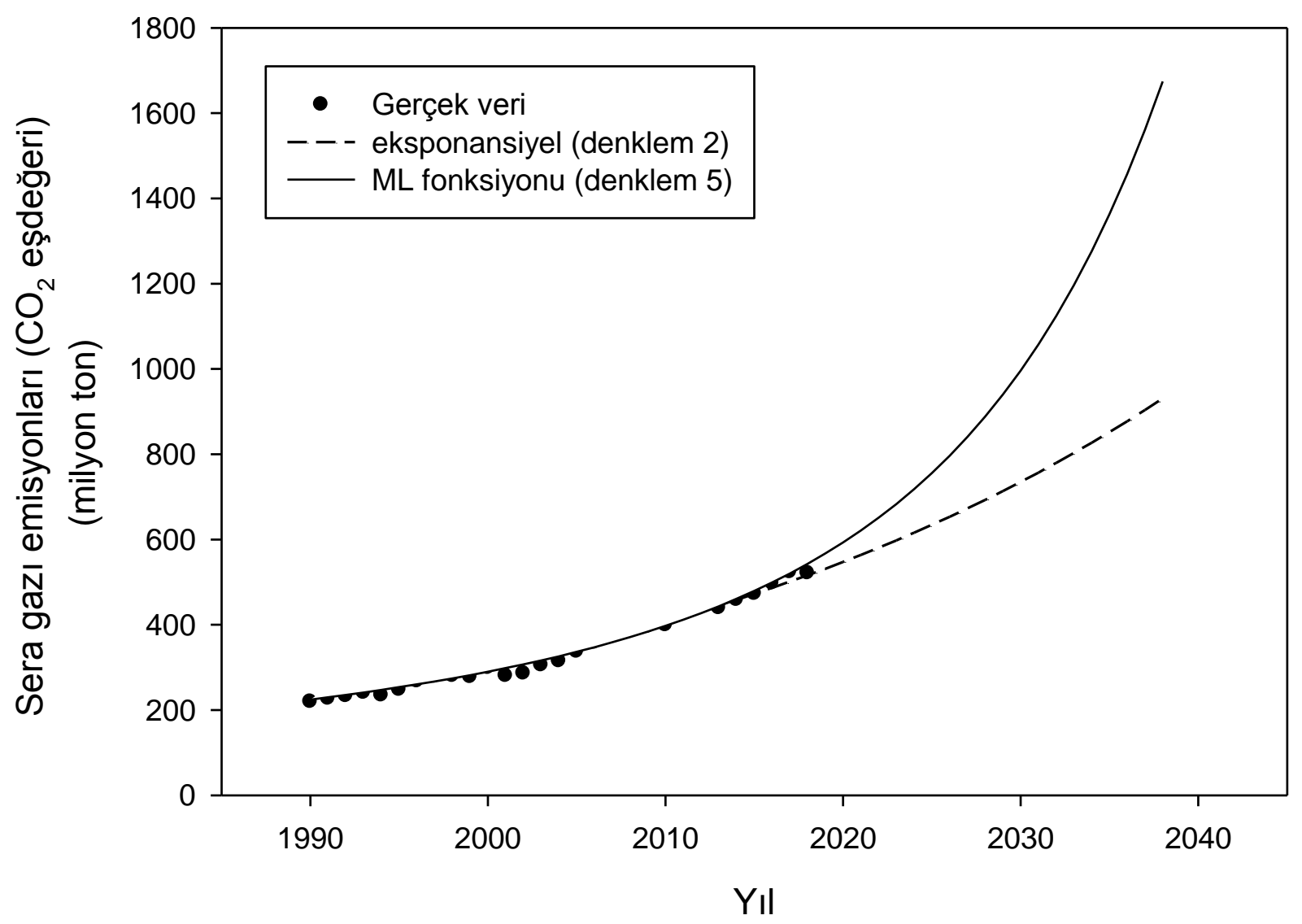

Şekil 1. Türkiye'deki sera gazı salınımının yıllara göre değişimi $(\alpha=0,305345)$.

\subsection{Nüfus}

Nüfus projeksiyonları hem ekonomik hem de sosyal açıdan büyük önem arz etmektedir. Türkiye İstatistik Kurumu da (TÜİK) bu nedenlerle nüfus projeksiyonları yapmaktadır. Eksponansiyel, doğrusal, polinomsal vb. birçok matematiksel yöntem ise özellikle kısa dönem nüfus tahminlerinde kullanılmaktadırlar (İskender 2018). Kesirsel matematiksel yöntemler de kısa veya uzun dönem tahminlerde kullanılabilecek yöntemlerden biridir. Şekil 2'de, $\alpha=0,305345$ ve $\lambda=0,01$ değeri için mevcut verilerden hareketle gelecek yıllara ait tahminler verilmektedir. Farklı senaryolar ile daha gerçekçi verilerin elde edilmesi olasıdır. Nüfus da diğer örneklerde olduğu gibi birçok etmene bağlıdır ve bu etmenleri de ele alarak daha ileri çalışmalar yapılabilir. 


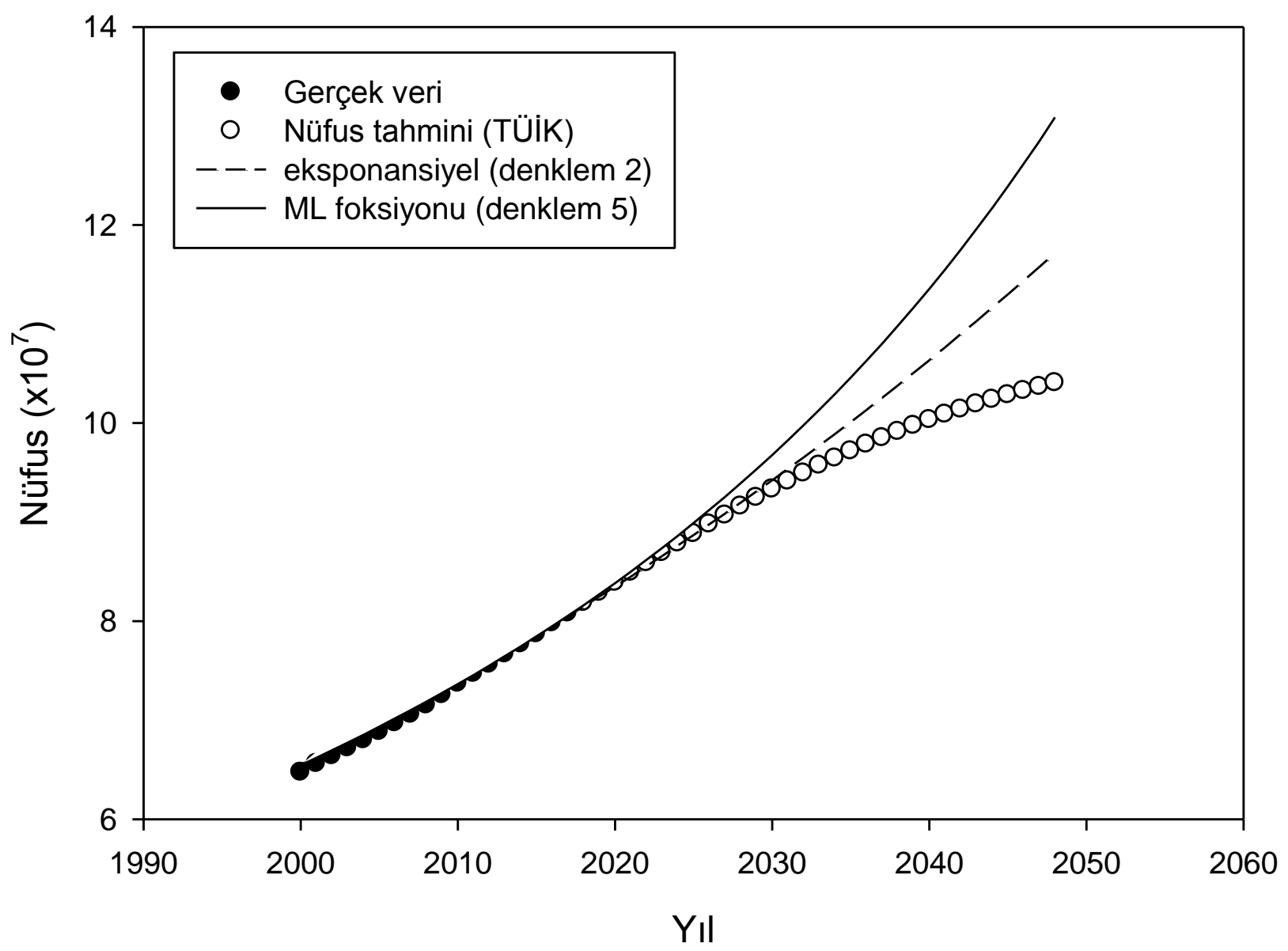

Şekil 2. Türkiye'nin nüfusunun yıllara göre değişimi ( $\alpha=0,305345)$.

\subsection{Dış Ticaret Hacmi}

Tüketim isteği, tüketim miktarları ve teknolojinin ilerlemesi ile dış ticaret hacmi her geçen yıl artmaktadır. Ülkeler için ihracatı artırıp ithalatı azaltmak önemli bir konudur. Bu nedenle de dış ticarete yönelik tahminlerde bulunmak her ülke için önem arz etmektedir. Literatürde diş ticaret hacminin tahminine yönelik çalışmalar sınırlı sayıdadır. Nüfus ve sera gazı uygulamalarında olduğu gibi birçok etken faktöre bağlıdır. Yurdakul 2014 yılındaki çalışmasında GSYİH, efektif döviz kuru, mal/hizmet ihracatı, yurtiçi kredi hacmi faktörleri altında yapay sinir ağları ile Türkiye'deki ithalatı tahmin etmeye çalışmıştır. Bu kesimde yıllara göre dış ticaret hacmi (özel ticaret), ML ve eksponansiyel fonksiyon yardımıyla incelemekte ve gerçek verilerle karşılaştırılmaktadır. Şekil 
3'de, $\alpha=0,305345$ ve $\lambda=0,02$ değeri için mevcut verilerden hareketle gelecek yıllara ait diş ticaret hacmi ile ilgili tahminler verilmektedir.

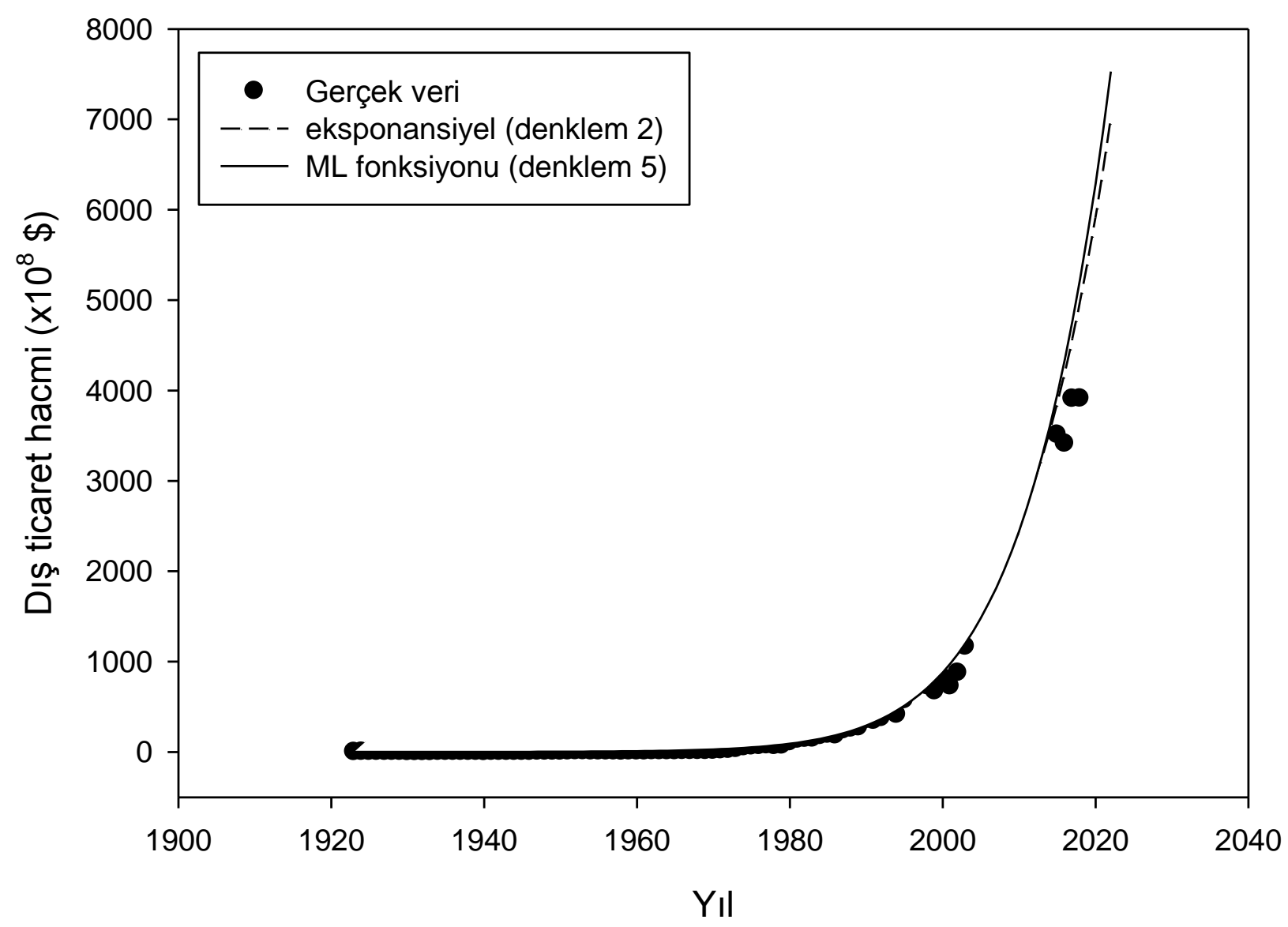

Şekil 3. Türkiye'nin diş ticaret hacminin yıllara göre değişimi $(\alpha=0,305345)$.

\section{Sonuçlar ve Öneriler}

İnsan davranışları doğanın geleceğinde önemli rol oynar. Bu davranışların doğa üzerindeki etkileri önceden tahmin etmek buna göre matematiksel bir model oluşturmak hem bilimsel çalışmalar hem de gelecek nesiller açısından önemlidir. Bu bağlamda fiziksel süreçlerin evriminin matematiksel modellenmesi ve geleceğe dönük tahmin yapılması önem arz etmektedir. Doğa ve yaşamda karşımıza çıkan birçok fiziksel süreç zaman ile artma veya azalma gösterir. Bu süreçleri temsil eden diferansiyel denklemlerden biri olan kinetik denklemin çözümünde karşımıza genellikle eksponansiyel fonksiyon ve türevleri çıkmaktadır. Süreçlerin dinamiğini anlamak, çalışılan sistemin gelecekteki durumunu araştırmak ve ona göre önlem almak veya yatırım yapmak açısından önemlidir. Örneğin sera gazı salınımı miktarının on yıllar sonraki durumunu tahmin etmek ve buna 
göre önlem almak veya diş ticaret hacminin ileriki yıllardaki durumunu tahmin ederek bu ihtiyaca yönelik uygun miktarda yatırım yapmaya olanak sağlamaktadır. Bu çalışmadaki amaç, sistemlerin incelenmesinde kesirsel matematiğin standart matematiğe göre daha kullanışlı ve doğru bir araç olduğudur. Çünkü, doğadaki kompleks davranış doğanın fraktal ve non-Markovian yapısını ihmal edilerek açıklanamaz. Başka bir deyişle, fiziksel süreçlerin zaman veya uzaydaki evrilmelerini standart matematiksel yöntemlerle incelemek bu süreçleri açıklamak için yeterli değildir. Gerçekte fiziksel süreçler Markovian ve Euclidian değildirler. Kesirsel matematiksel yöntemler içinde ise fraktal ve non-Markovian özellikleri doğal olarak içinde barındıran yararlı matematiksel araçlardır. Bu bağlamda, yaşam ve doğadan alınan Türkiye'deki nüfus artışı, sera gazı salınım miktarları ve dış ticaret hacmi örneklerine ait veriler kesirsel matematiksel çözümlerde sıkça karşımıza çıkan ML fonksiyonu yardımıyla ele alınmıştır. Doğadaki veya yaşamdaki verilerle elde edilen grafikler kesirsel türev mertebesi $\alpha$ ve mevcut başlangıç koşulları ile çizdirilmiştir. Şekil 1, 2 ve 3 'ten görüleceği gibi $\alpha \sim 0,35$ ve $\lambda \sim 0,1-0,2$ değerleri ve başlangıç koşuları için (5) denklemi, gerçek değerler ile eksponansiyel fonksiyona göre daha iyi bir uyum içerisindedir. Bu bağlamda denilebilir ki, hangi tahmin metodu kullanılırsa kullanılsın standart matematiksel yöntemler yerine kesirsel olanlar tercih edilmelidir. Sonuç olarak doğanın fraktal ve non-Markovian yapısı sebebiyle standart matematik yerine kesirsel matematik, eksponansiyel fonksiyon yerine onu genelleyen ML fonksiyonu tercih edilmesi daha doğru gözükmektedir.

\section{Kaynaklar}

Boğar, E. ve Boğar, Z. Ö., (2017). Türkiye'nin Sektörel CO2 Gazı Salınımlarının Yapay Sinir Ağları ile Tahmini, Akademia Disiplinlerarası Bilimsel Araştırmalar Dergisi, 3 (2), 12-24.

Bowen, W.D., McMillan, J and Mohn, R., (2003). Sustained exponential population growth of grey seals at Sable Island, Nova Scotia, ICES Journal of Marine Science, 60, 6, 1265-1274.

Büyükkılıç, F. and Demirhan, D., (2009). Cumulative growth with fibonacci approach, golden section and physics, Chaos, Solitons and Fractals, 42, 24-32.

Büyükkılıç, F., Ok Bayrakdar, Z. and Demirhan, D., (2016). Investigation of the Cumulative Diminution Process Using the Fibonacci Method and Fractional Calculus, Physica A: Statistical Mechanics and its Applications, 444, 336-344.

Büyükkılıç. F., Ok Bayrakdar, Z. and Demirhan, D.,( 2015). Investigation of Cumulative Growth Process via Fibonacci Method and Fractional Calculus, Applied Mathematics and Computation, 265, 237-244.

Çalık, A. E., Ertik, H., Öder, B. and Şirin, H., (2013). A fractional calculus approach to investigate the alpha decay processes, International Journal of Modern Physics E, 22 (7), 1350049.

Çalık, A. E., Şirin, H., Ertik, H. and Şen, M., (2016). Analysis of charge variation in fractional order LC electrical circuit, Revista Mexicane de Fisica 62, 437.

Çalık, A. E., Şirin, H., Ertik, H., Öder, B. and Şen, M., (2014). Half-lives of Spherical Proton Emitters within the Framework of Fractional Calculus, International Journal of Modern Physics E, 23 (9), 1450044.

Çalık, A.E. ve Şirin, H., (2017). Türkiye'deki elektrik enerji ihtiyacının matematiksel bir modellemesi, Sakarya Üniversitesi Fen Bilimleri Enstitüsü Dergisi, 21(6), 1475-1482. 
Şirin, H., Çalık, A. E., Uluslararası Doğu Anadolu Fen Mühendislik ve Tasarım Dergisi / International Journal of Eastern Anatolia Science Engineering and Design (IJEASED)

(2020) 2(2):262-274

Çalık, A.E. ve Şirin, H., (2018). Farklı tipte üretilen harçların yarı-değer kalınlıklarının teorik olarak incelenmesi, Anadolu Üniversitesi Bilim ve Teknoloji Dergisi B-Teorik Bilimler, 6(1), 36-44.

Çalık, A.E., Şirin, H. and Şen, M., (2020). Experimental and fractional analysis of half-value thicknesses of polyethylene absorber, Revista Mexicane de Fisica, 66 (2), 232-238.

Çeşmeli, M. Ş. ve Pençe, İ., (2020). Makine Öğrenimi Yöntemleri ile Türkiye için Sera Gazı Emisyonu Tahmini, Academic Platform Journal of Engineering and Science, 8-2, 332-348.

Ertik, H., Çalık, A. E., Şirin, H., Şen, M. and Öder, B., (2015). Investigation of electrical RC circuit within the framework of fractional calculus, Revista Mexicane de Fisica, 61, 58.

Haubold, H. J. and Mathai, A.M., (2000). The fractional kinetic equation and thermonuclear functions, Astrophysics and Space Science 327, 53-63.

Herrmann, R., (2011). Fractional Calculus: An Introduction for Physicists, World Scientific.

Hilfer, R., (2000). Applications of Fractional Calculus In Physics, World Scientific.

Hilfer, R., (2003). On fractional relaxation, Fractals, Vol. 11, Supplementary Issue, 251-257.

Holland, R.R., Ellis, C. A., Geller, B. M., Plante, D.A. and Secker-Walker, R.H., (1999). Life Expectancy Estimation with Breast Cancer: Bias of the Declining Exponential Function and an Alternative to Its Use, Medical Decision Making, 19, 4, 385-393.

İskender, C., (2018). Türkiye Nüfus Büyümesi ve Tahminleri: Matematiksel Büyüme Modelleri ve İstatistiksel Analiz ile Kuramsal ve Uygulamalı Bir Yaklaşım, Ekonometri ve Ístatistik e-Dergisi, 14(28): 75-141.

Keeling, M. J., (2000). Simple stochastic models and their power-law type behaviour. Theoretical Population Biology 58, 21-31.

Keiding, N., (1975). Extinction and Exponential Growth in Random Environments, Theoretical Population Biology, 8 (1), 49-63.

Keitt, T. H. and Stanley, H. E., (1998). Dynamics of North American breeding bird populations. Nature 393, $257-260$.

Keitt, T. H., Amaral, L. A. N., Buldyrev, S. V. and Stanley, H. E., (2002). Scaling in the growth of geographically subdivided populations: invariant patterns from a continent-wide biological survey. Philosophical Transactions B, 357, 627-633.

Krane, K. S. (1988). Introductory Nuclear Physics, John Wiley and Sons.

Marquet, P. A., Quiñones, R. A., Abades, S., Labra, F., Tognelli, M., Arim and M, Rivadeneira, M., (2005). Scaling and power-laws in ecological systems, Journal of Experimental Biology, 208: 1749-1769.

Martinez, A.S., Gonzales, R.S. and Espindola A.L., (2009). Generalized exponential function and discrete growth models, Physica A: Statistical Mechanics and its Applications, 388, 2922-2930.

Miller K. S. and Ross B., (1993). An Introduction to the Fractional Calculus and Fractional Differential Equations, John Wiley and Sons Inc.

Nivanen, L., Mehaute, A. and Wang Q.A., (2003). Generalized algebra within a nonextensive statistics, Reports on Mathematical Physics, 52, 437-444.

Oldham K. B. and Spanier, J., (2006). The Fractional Calculus: Theory and Applications of Differentiation and Integration to Arbitrary Order, Dover Publications.

Pabuçcu, H. ve Bayramoğlu, T., (2016). Yapay Sinir Ağları ile CO2 emisyonu tahmini: Türkiye örneği, Gazi Üniversitesi İktisadi ve İdari Bilimler Fakültesi Dergisi, 18 (3), 762-778.

Podlubny I., (1999). Fractional Differential Equations, Academic Press.

Ricketts, J. H. and Head, G. A., (1999). A five-parameter logistic equation for investigating asymmetry of curvature in baroreflex studies. American Journal of Physiology - Regulatory, Integrative and Comparative Physiology, 277 (2), 441-454.

Sabatelli, L., Keating, S., Dudley, J. And Richmond, P., (2002). Waiting time distributions in financial markets, The European Physical Journal B, 27, 273-275.

Saxena, R., Mathai, A. and Haubold, H., (2002). On fractional kinetic equations, Astrophysics and Space Science, 282, 281-287.

Shimojo, M., (2014). An Application of Bondi K-Factor to the Preliminary Investigation into Some Natural Phenomena, Journal of the Faculty of Agriculture, Kyushu University, 59 (2), 301-303. 
Shimojo, M., Nakano Y., (2013). An investigation into relationships between exponential functions and some natural phenomena, Journal of the Faculty of Agriculture, Kyushu University, 58 (1), 51-53.

Sibonga, J.D., Evans, H.J., Sung, H.G., Spector, E.R., Lang, T.F., Oganov, V.S., Bakulin, A.V., Shackelford, L.C., LeBlanc, A.D., (2007). Recovery of spaceflight-induced bone loss: Bone mineral density after long-duration missions as fitted with an exponential function, Bone, 41 (6), 973-978.

Silva, C. A, Prange, R. E. and Yakovenko V. M., (2004). Exponential distribution of financial returns at mesoscopic time lags: a new stylized fact, Physica A 344, 227-235.

Stanley, M. H. R., Amaral, L. A. N., Buldyrev, S. V., Havlin, S., Leschhorn, H., Maass, P., Salinger, M. A. \& Stanley, H. E. (1996). Scaling behavior in the growth of companies. Nature 379,804 -806.

Şen, M. and Çalık, A. E., (2014). Calculation of Half-Value Thickness for Aluminum Absorbers by Means of Fractional Calculus, Annals of Nuclear Energy, 63, 46-50.

Şen, M., Çalık A. E., and Ertik, H., (2014). Determination of half-value thickness of aluminum foils for different beta sources by using fractional calculus, Nuclear Instruments and Methods in Physics Research Section B: Beam Interactions with Materials and Atoms, 335, 78-84.

Şen, M., Çalık, A.E. and Şirin, H., (2019). Theoretical investigation of tenth-value thicknesses of aluminium absorbers, AIP Conference Proceedings, 2178, 030058.

Şirin, H. \& Çalık, A.E. (2019). Newton'un Soğuma Kanunu: Kesirsel Bir Yaklaşım, Afyon Kocatepe Üniversitesi Fen ve Mühendislik Bilimleri Dergisi, 19, 60-66.

Vacher, H.L., (2000). The Exponential Function, Journal of Geoscience Education, 48 (1), 70-77.

Vandermeer, J., (2010). How Populations Grow: The Exponential and Logistic Equations, Nature Education Knowledge 3(10), 15.

Verma, K.M., Asad, A. and Chatterjee S. (2020). COVID-19 Pandemic: Power Law Spread and Flattening of the Curve, Transactions of the Indian National Academy of Engineerin, 5, 103-108.

Yurdakul, E. M. (2014). Türkiye'de İthalatın Gelişimi ve İthalatın Yapay Sinir Ağları Yöntemi Ile Tahmin Edilebilirliğine Yönelik Bir Analiz, Doktora Tezi, Sosyal Bilimler Enstitüsü, Adnan Menderes Üniversitesi, Aydın. 